\title{
Pleiotropic Effects of Simvastatin Are Associated With Mitigation of Apoptotic Component of Cell Death Upon Lethal Myocardial Reperfusion-Induced Injury
}

\author{
T. RAJTÍK ${ }^{1}$, S. ČARNICKÁ ${ }^{2}$, A. SZOBI ${ }^{1}$, L. MESÁROŠOVÁ ${ }^{3}$, M. MÁŤUŠ ${ }^{1}$, P. ŠVEC $^{1}$, \\ T. RAVINGEROVÁ ${ }^{2}$, A. ADAMEOVÁ ${ }^{1}$
}

${ }^{1}$ Department of Pharmacology and Toxicology, Faculty of Pharmacy, Comenius University, Bratislava, ${ }^{2}$ Institute for Heart Research, Slovak Academy of Sciences and Centre of Excellence, SAS NOREG, Bratislava, ${ }^{3}$ Faculty of Medicine, Comenius University, Martin, Slovak Republic

Received March 20, 2012

Accepted June 28, 2012

\begin{abstract}
Summary
Although statins exert non-lipid cardioprotective effects, their influence on cell death is not fully elucidated. For this purpose, we investigated whether simvastatin treatment $(\mathrm{S}, 10 \mathrm{mg} / \mathrm{kg}$, 5 days) is capable of mitigating ischemia/reperfusion-induced (IR) apoptosis in the isolated rat hearts, which was examined using immunoblotting analysis. In addition, the content of signal transducer and activator of transcription 3 (STAT3) and its active form, phosphorylated STAT3 (pSTAT3-Thr ${ }^{705}$ ), was analyzed. Simvastatin induced neither variations in the plasma lipid levels nor alterations in the baseline content of analysed proteins with the exception of upregulation of cytochrome C. Furthermore, simvastatin significantly increased the baseline levels of pSTAT3 in contrast to the control group. In the IR hearts, simvastatin reduced the expression of Bax and non-cleaved caspase-3. In these hearts, phosphorylation of STAT3 did not differ in comparison to the non-treated IR group, however total STAT3 content was slightly increased. The improved recovery of left ventricular developed pressure co-existed with the increased Bcl2/Bax ratio. In conclusion, pleiotropic action of statins may ameliorate viability of cardiomyocytes by favouring the expression of anti-apoptotic Bcl-2 and downregulating the proapoptotic markers; however STAT3 does not seem to be a dominant regulator of this anti-apoptotic action of simvastatin.
\end{abstract}

\section{Key words}

Cell death • Apoptosis • Myocardial ischemia-reperfusion injury • Statins $\bullet$ STAT3

\begin{abstract}
Corresponding author
Adriana Adameova, Department of Pharmacology and Toxicology, Faculty of Pharmacy, Comenius University, Odbojarov 10, 83232 Batislava, Slovak Republic. Fax: +421 250117100 . E-mail: adameova@fpharm.uniba.sk
\end{abstract}

\section{Introduction}

It has become increasingly apparent that lipoprotein metabolism modification alone cannot explain all benefits associated with statin treatment. Non-lipid, so-called pleiotropic effects of statins determined by the inhibition of post-translational modification of small $\mathrm{G}$ proteins of the Ras/Rho family, have been suggested to reduce cardiovascular disease risk (Wright and Flapan 1994), progression of nephropathy, development of diabetes (Tonolo et al. 2000, Freeman et al. 2001) and fracture rates (Meier et al. 2000). In addition, statinmediated cardioprotection against ischemia/reperfusion injury (IRI), a phenomenon observed following thrombolytic therapy of acute myocardial infarction, angioplasty and cardiac surgery, has also been reported. Different statins have exerted beneficial effects when given before ischemia (Adameova et al. 2009, Ravingerova et al. 2010, Ikeda et al. 2003), or even early upon the onset of reperfusion (Vilahur et al. 2009, Bell and Yellon 2003).

Although IRI refers to early restoration of blood to previously ischemic heart, which is required to salvage viable tissue, it can paradoxically cause cardiomyocyte 
death (Braunwald and Kloner 1985). Both apoptosis and necrosis are implicated into the pathophysiology of IRI; however contribution of each to cardiomyocyte death is controversial. Some studies have suggested that apoptosis is induced by ischemia in the absence of reperfusion (Fliss and Gattinger 1996, Kajstura et al. 1996), while other studies have demonstrated that it is triggered during reperfusion and does not manifest during ischemia (Zhao et al. 2000) or that reperfusion accelerates apoptosis initiated during ischemia (Fliss and Gattinger 1996, Freude et al. 2000). The two types of IRI-induced cell death are distinct. Necrotic cell death is characterized by membrane disruption, cell swelling, lysis and inflammatory response, while apoptosis results in DNA fragmentation, prevents inflammation and preserves membrane integrity (Fiers et al. 1999). In response to an apoptotic stimulus, cytochrome $\mathrm{C}$ and other pro-apoptotic factors are released through mitochondrial permeability transition pore (mPTP) into the cytoplasm to form apoptosome that in turn activates caspase 3 to drive the execution phase of apoptosis (Danial and Korsmeyer 2004). mPTP forming and opening is regulated by Bcl-2 family proteins; indeed predominance of anti-apoptotic factors (Bcl-2, Bcl-xL) over the apoptotic ones (Bax, $\mathrm{Bad})$ preserves mPTP opening. It has been shown that the genes encoding proteins of Bcl-2 family are modified by a transcription factor signal transducer and activator of transcription 3 (STAT3), activation of which is in turn directly/indirectly regulated by the small GTP-binding Rho family (Simon et al. 2000, Faruqi et al. 2001). In settings of IRI, activation of STAT3 has been suggested to reduce cell death, attenuate adverse cardiac remodelling (Boengler et al. 2008, Obana et al. 2010) and participate in preconditioning-mediated cardioprotection (Hattori et al. 2001).

Based on this, we have hypothesized that inhibition of HMG-CoA reductase, and thereby its downstream changes in prenylation of the Rho/Ras family, may limit the intrinsic IRI-induced apoptotic pathway through STAT3 responsive anti-apoptotic genes. Furthermore, as loss of cells has impact on cardiac performance, a link between Bcl-2/Bax ratio and the postischemic recovery of left ventricle developed pressure upon IRI has been investigated.

\section{Methods}

Animals

Male Wistar rats (250-300 g body weight) were housed under standard conditions with a constant 12:12 h light/dark cycle (lights on at $06.00 \mathrm{~h}$ ) and temperature $\left(22^{\circ} \mathrm{C} \pm 2{ }^{\circ} \mathrm{C}\right)$, and fed a standard diet and tap water $a d$ libitum. The protocol of the research project has been approved by the Ethics Committee of the Faculty of Pharmacy, Comenius University. All studies were performed in accordance with the Guide for the Care and Use of Laboratory Animals published by US National Institutes of Health (NIH publication No 85-23, revised 1996) and approved by the Animal Care and Animal Welfare Division of the State Veterinary and Food Administration of the Slovak Republic.

\section{Drug used in the studies}

Simvastatin (S) was given at a single daily dose of $10 \mathrm{mg} / \mathrm{kg}$ during 5 days per os. The rationale for the used dosage was based on the previous evidence that this treatment exerts cardioprotection associated with pleiotropic non-hypolipidemic activity of the drug (Adameova et al. 2009, Ravingerova et al. 2009).

After 5-day treatment, rats were divided into the following groups: the simvastatin-treated non-ischemic group (CS) and the simvastatin-treated group subjected to the protocol of ischemia and reperfusion (CS+IR) as described below. The same IRI protocol was applied for a separate group of nontreated animals $(\mathrm{C}+\mathrm{IR})$ which were compared with the non-ischemic control group (C).

\section{Perfusion technique and protocol of ischemia/reperfusion} injury

The hearts of anaesthetized (sodium pentobarbitone, $60 \mathrm{mg} / \mathrm{kg}$, i.p) animals were rapidly excised and perfused at $37^{\circ} \mathrm{C}$ in the Langendorff mode at a constant perfusion pressure of $70 \mathrm{mmHg}$ for 30 minutes. The perfusion solution was a modified Krebs-Henseleit buffer (KHB) gassed with $95 \% \mathrm{O}_{2}$ and $5 \% \mathrm{CO}_{2}$ (pH 7.4) containing (in $\mathrm{mM}$ ): $\mathrm{NaCl} 118.0 ; \mathrm{KCl}$ 3.2; $\mathrm{MgSO}_{4} 1.2 ; \mathrm{NaHCO}_{3} 25.0 ; \mathrm{KH}_{2} \mathrm{PO}_{4} 1.18 ; \mathrm{CaCl}_{2} 2.5$; glucose 5.5. After stabilization period, global ischemia was induced by clamping of the aortic inflow for $30 \mathrm{~min}$ followed by $40 \mathrm{~min}$ of reperfusion. Hearts of both nonischemic groups were subjected to the same procedure except of induction of ischemia and reperfusion.

Left ventricular (LV) pressure was measured by means of a non-elastic water-filled balloon inserted into the LV cavity (adjusted to obtain end-diastolic pressure of $5-7 \mathrm{mmHg}$ ) and connected to a pressure transducer (MLP844, ADInstruments, Germany). LV developed pressure (LVDP; systolic minus diastolic pressure) was 
measured during stabilization, preischaemic period and continuously recorded until the end of experiment using PowerLab/8SP Chart 7 software (ADInstruments, Germany). LVDP recovery at $40 \mathrm{~min}$ of reperfusion was expressed as percentage of pre-ischemic baseline values and was used to evaluate the link between the postischemic functional recovery and apoptotic cell death.

\section{Immunoblotting}

Left ventricular samples from S-treated and non-treated non-ischemic hearts as well as hearts subjected to global ischemia and reperfusion were frozen in liquid nitrogen and stored at $-80{ }^{\circ} \mathrm{C}$ until further processing. Proteins were separated by SDSPAGE on 10-14\% polyacrylamide gels and transferred electrophoretically onto polyvinylidene fluoride membrane (PVDF, Immobilon-P, Millipore Corp., Billerica, MA, USA). Nonspecific binding sites were blocked with either $5 \%(\mathrm{w} / \mathrm{v})$ nonfat milk powder or $2 \%(\mathrm{w} / \mathrm{v})$ bovine serum albumin (BSA) in TBST buffer. Membranes were incubated with different primary antibodies diluted in $1 \%$ milk and $2 \%$ BSA for analysis of non-phosphorylated and phosphorylated proteins, respectively. $\beta$-actin (antibody purchased from SigmaAldrich, USA) was used for a loading control. Primary antibody for both pro- and anti-apoptotic proteins (Bax, Bcl-2, CytC, caspase 3, STAT3 and pSTAT3-Thr ${ }^{705}$ ) were $\operatorname{IgG}$ antibodies raised in rabbit or mice (Sigma Aldrich, USA). Secondary antibodies were anti-rabbit and anti-mouse conjugated with horseradish peroxidase (Jackson ImmunoResearch, United Kingdom, and Santa Cruz Biotechnology, USA). Bands were detected by enhanced chemiluminescence (Pierce ECL Western Blotting Substrate, USA) and blots were quantified by scanning densitometry.

\section{Statistical analysis}

Data were expressed as means \pm S.E.M. for the number (n) of animals in the group. ANOVA and twotailed unpaired Student's $t$-test were applied for comparison of differences in variables with normal distribution between the groups using GraphPad Prism version 5.00 for Windows (GraphPad Software, San Diego CA, USA). Correlation between recovery of LVDP and Bcl-2/Bax ratio was made by Pearson's test. Differences between the groups were considered as significant at $P<0.05$.

\section{Results}

Plasma lipid, glucose levels and weight parameters

As shown in Table 1, simvastatin treatment at given dose had no influence on the main weight parameters. In addition, no variations in the plasma lipid levels were found between the S-treated and non-treated normocholesterolemic rats, confirming that observed Smediated effects are due to its pleiotropic activity. Likewise, the plasma glucose levels were not changed upon $\mathrm{S}$ treatment.

Table 1. The effects of simvastatin treatment on basic weight parameters, plasma lipid and glucose levels in rats fed with a standard diet.

\begin{tabular}{lcr}
\hline & $\mathbf{C}$ & \multicolumn{1}{c}{ CS } \\
\hline$B W(g)$ & $247.50 \pm 12.63$ & $233.33 \pm 9.20$ \\
$H W(g)$ & $0.82 \pm 0.02$ & $0.83 \pm 0.02$ \\
$L V W(g)$ & $0.38 \pm 0.03$ & $0.35 \pm 0.02$ \\
\hline TCHOL (mmol/l) & $1.27 \pm 0.06$ & $1.34 \pm 0.12$ \\
VLDL (mmol/l) & $0.21 \pm 0.05$ & $0.20 \pm 0.01$ \\
$L D L(\mathrm{mmol} / \mathrm{l})$ & $0.28 \pm 0.01$ & $0.26 \pm 0.04$ \\
$H D L(\mathrm{mmol} / \mathrm{l})$ & $0.69 \pm 0.11$ & $0.80 \pm 0.06$ \\
$T A G(\mathrm{mmol} / \mathrm{l})$ & $0.59 \pm 0.12$ & $0.44 \pm 0.03$ \\
$G L U(\mathrm{mmol} / \mathrm{l})$ & $8.79 \pm 2.69$ & $7.37 \pm 1.29$ \\
\hline
\end{tabular}

BW - body weight; HW - heart weight; LVW - left ventricle weight; TCHOL - total cholesterol; LDL - low density lipoproteins; HDL - high density lipoproteins; VLDL - very low density lipoproteins. Values are means \pm S.E.M. from 12 animals per group.

Influence of simvastatin treatment on apoptotic cell death

To find out whether $\mathrm{S}$ treatment may modulate apoptotic cell death, we used immunoblotting analysis of selected pro- and anti-apoptotic proteins (Fig. 1). Semiquantitative data of protein expression in the non-treated and treated hearts as well as in the hearts subjected to IRI are shown in Figure 2. In the non-ischemic left ventricle of the S-treated rats, expression of cyt $\mathrm{C}$ was increased; however, in the ischemic hearts simvastatin treatment reduced cyt $\mathrm{C}$ levels $(P<0.05)$. Under baseline conditions protein levels of non-cleaved caspase-3 were not changed by $\mathrm{S}$ treatment. In contrast, $\mathrm{S}$ induced a decrease in the non-cleaved protein content in the hearts subjected to IRI $(P<0.05)$. These protein levels were lower than the levels in the non-treated IR hearts $(P<0.05)$. 


\section{C+IR CS CS+IR}

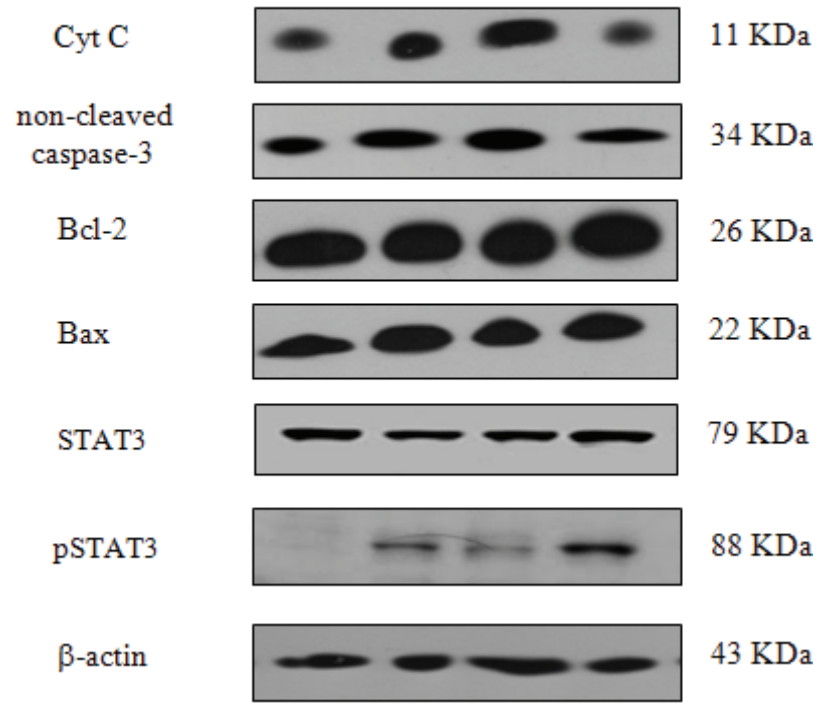

Fig. 1. The effects of simvastatin treatment on protein content of some markers of the intrinsic apoptotic death and signal transducer and activator of transcription (STAT3) in the left ventricle of the non-ischemic hearts (CS) and of the hearts subjected to ischemia/reperfusion injury (CS+IR). Representative imunoblots of the transcription factor STAT3, cytochrome C (Cyt C), non-cleaved caspase-3, Bcl-2, and Bax.

Furthermore, we analyzed the expression of proteins of Bcl-2 family (Figure 1,2). Simvastatin treatment did not change the expression of anti-apoptotic Bcl-2. However, in the ischemic hearts, it upregulated the Bcl-2 content in comparison to the levels in the nontreated ischemic hearts $(\mathrm{P}<0.05)$. In contrast, expression of pro-apoptotic Bax showed a reversed trend. The increased Bax levels in the IR hearts were downregulated by $\mathrm{S}(\mathrm{P}<0.05)$. Statistical analysis of $\mathrm{Bcl}-2 / \mathrm{Bax}$ ratio revealed that the non-treated hearts subjected to IR are likely to be more sensitive to apoptosis (evidenced by a lower ratio), while S-treated hearts may be more resistant against this type of cell death. Simvastatin did not completely reverse this ratio to the baseline levels; however it was increased in comparison to ratio in the non-treated $\mathrm{I} / \mathrm{R}$ hearts $(\mathrm{P}<0.05)$, implicating antiapoptotic effects of simvastatin.

The levels of total STAT3 were changed by neither ischemia/reperfusion nor by statin treatment (Figure 1,2). Simvastatin treatment significantly increased the baseline content of pSTAT3 in comparison to the control group $(\mathrm{P}<0.05)$. However, there was no significant difference with respect to the content of pSTAT3 between the treated and the non-treated IR group.
Link between Bcl-2/Bax ratio and recovery of left ventricle developed pressure upon simvastatin treatment

Contractile function of the heart subjected to IRI was improved in the S-treated hearts $(\mathrm{P}<0.05)$. Correlation between Bcl-2/Bax ratio and LVDP recovery was not significant; however, it is evident that in the Streated group that higher $\mathrm{Bcl}-2 / \mathrm{Bax}$ ratio co-existed with improved contractile function of the heart (Fig. 3).

\section{Discussion}

In the present study, we showed that HMG-CoA reductase inhibition by simvastatin given orally for 5 days before induction of IRI is associated with abolishment of apoptotic cell death. Namely, in the hearts subjected to IRI, simvastatin decreased the expression of the pro-apoptotic Bax, increased the levels of the antiapoptotic marker Bcl-2. In addition, Bcl-2/Bax ratio, which was higher in the S-treated IR hearts, co-existed with the improved contractile function evidenced by the higher post-ischemic recovery of LVDP. Under basal conditions, $\mathrm{S}$ treatment increased expression of cyt $\mathrm{C}$, but had no effect on the content of Bax, Bcl-2, and procaspase-3. Although the total non-phosphorylated STAT3 did not differ among the groups, simvastatin treatment up-regulated the content of pSTAT3, suggesting its ability to modulate expression of the proteins, including the apoptotic proteins, through this transcription factor. On the other hand, such an increase in pSTAT3 induced by simvastatin was not observed in the treated IR group.

The extent of cell death upon IRI is a major determinant of mortality and post-ischemic remodelling. Hence, strategies for the amelioration/preservation of myocardial cell viability are a matter of interest of many cardiologists. Statins, besides a wide spectrum of potential substances, have been suggested to be promising agents with the ability to reduce cell death due to IRI (Webster 2007). Using experimental animal model of acute IRI, it is possible to investigate the effects of statins at different time-points, and thus it can provide valuable information for clinical application. In fact, preischemic statin treatment is limited to the clinical settings of planned cardiac surgery or elective percutaneous coronary intervention, while statin administration upon reperfusion may be limited to thrombolytic therapy after myocardial infarction. In our previous studies, we used 5day simvastatin-treated rats that are less sensitive to reperfusion-induced arrhythmias and cardiac stunning (Adameova et al. 2009, Ravingerova et al. 2010). 
non-cleaved caspase-3

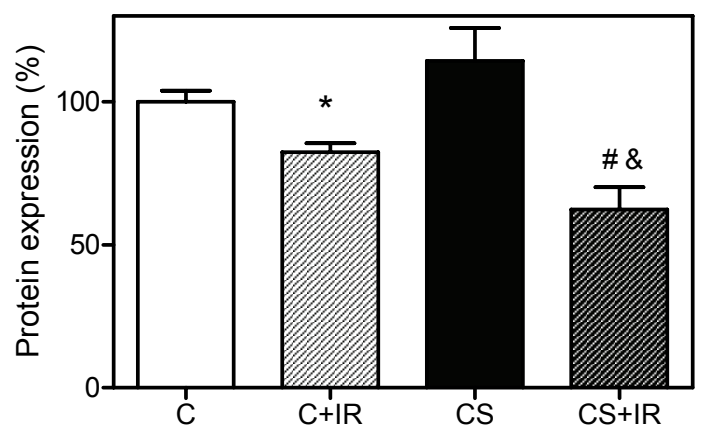

Bcl-2

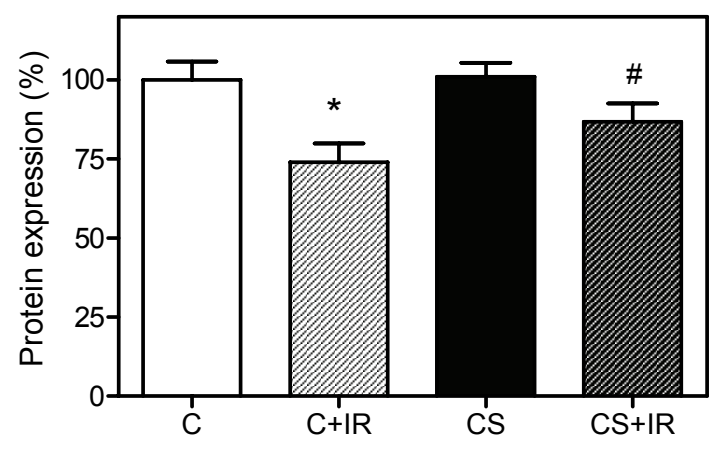

Bax

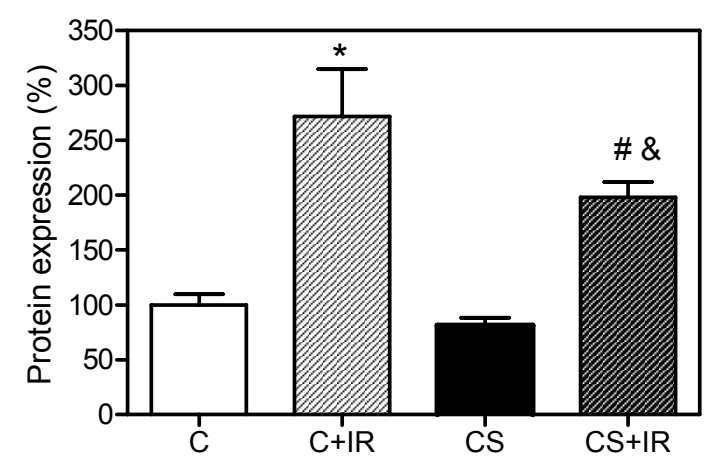

Bcl-2/Bax ratio

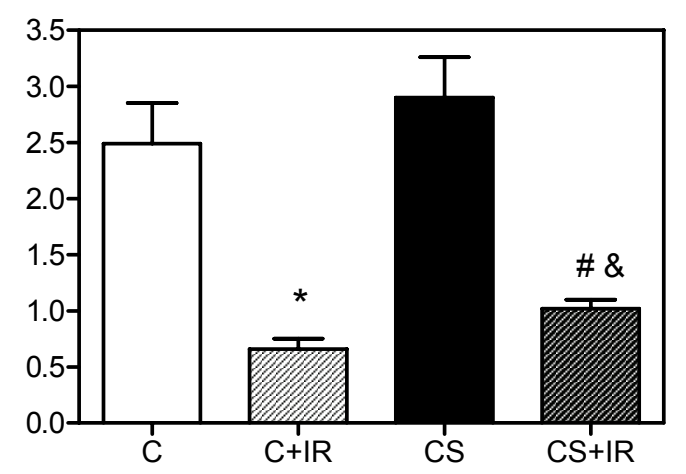

Cytochrome C
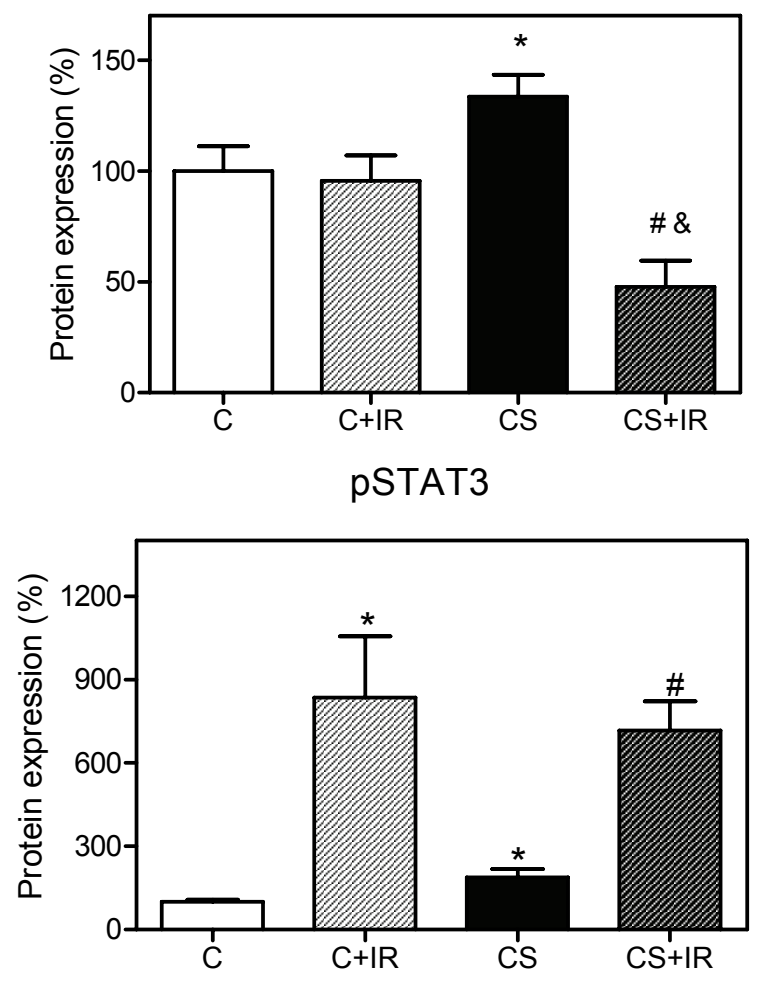

STAT3

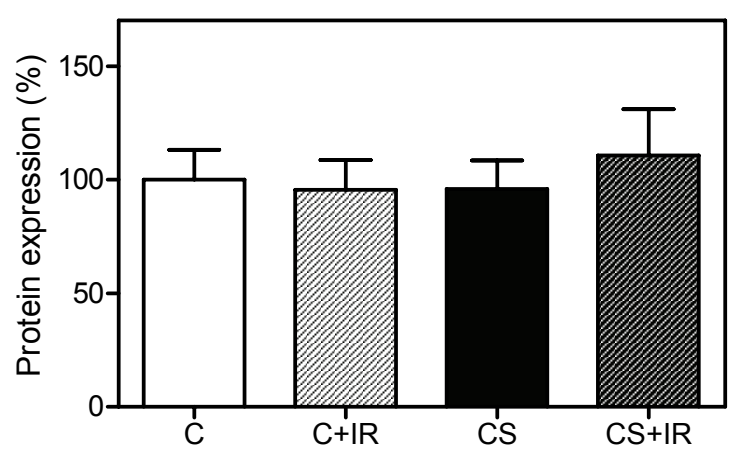

pSTAT3/STAT3 ratio

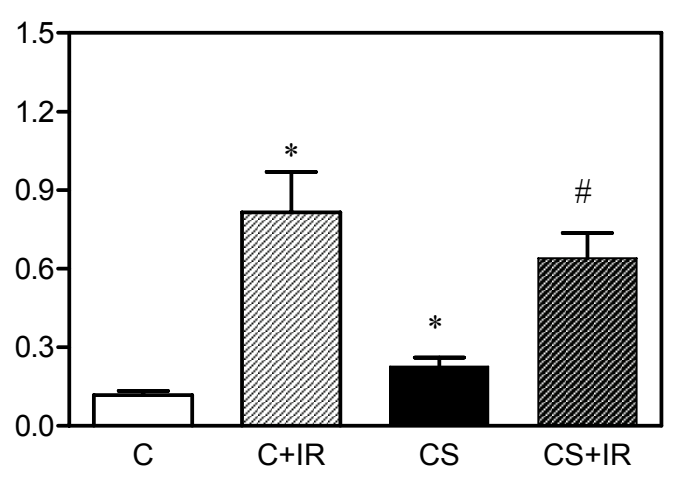

Fig. 2. The effects of simvastatin treatment on protein content of some markers of the intrinsic apoptotic death and signal transducer and activator of transcription (STAT3) in the left ventricle of the non-ischemic hearts (CS) and of the hearts subjected to ischemia/reperfusion injury (CS+IR). Quantification of imunoblotting analysis, Bcl-2/Bax ratio and pSTAT3/STAT3 ratio. Values are means \pm S.E.M. from 5-7 hearts per group. ${ }^{*} \mathrm{P}<0.05$ vs. non-ischemic controls $(\mathrm{C}),{ }^{*} \mathrm{P}<0.05$ vs. S-treated hearts, ${ }^{\&} \mathrm{P}<0.05$ vs. nontreated ischemic/reperfused hearts. 


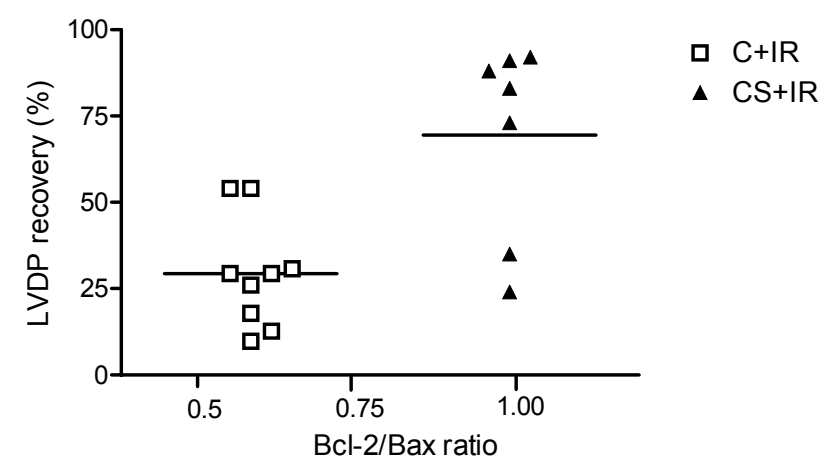

Fig. 3. Recovery of left ventricle developed pressure (LVDP) dependent on the distribution of $\mathrm{BCl}-2 / \mathrm{Bax}$ ratio in the simvastatin-treated and non-treated hearts subjected to ischemia/reperfusion.

In the present study, using the same protocol, we have extended our knowledge about cardioprotection of pre-ischemic statin treatment on IRI-induced cell death. Beneficial effects of statin treatment on programmed death were accompanied by the lower extent of necrosis (Adameova et al. 2009). This aspect of S-mediated cardioprotection is believed to be due to its pleiotropic action, because no changes in the plasma cholesterol and lipid levels were observed between the treated and nontreated group (Table 1). However, it should be mentioned that results of clinical studies regarding pleiotropic beneficial effects of statins are not clear. In statin-treated patients undergoing coronary artery bypass graft surgery, the incidence of ventricular arrhythmias, atrial fibrillations and cardiovascular mortality were reduced, however the incidence of postoperative MI, stroke or renal failure were not significantly changed (Liakopoulous et al. 2009, Pan et al. 2004).

Mechanisms underlying statin-induced cardioprotection on cell death are still a subject of investigation and it is apparent that anti-apoptotic mechanisms differ from those preventing necrosis, nonetheless a cross-link between them cannot be ruled out. Besides other potential mechanisms, statin-mediated inhibition of the formation of mevalonate and thus isoprenoids prenylating Ras/Rho family, which act via nuclear factor kappa $\mathrm{B}$, has been suggested to limit inflammatory response to IRI and thereby it can limit, in particular, the necrotic component of cardiomyocyte death (Hernandez-Presa et al. 2003). In addition, nitric oxide (NO) is considered to be a critical signalling molecule involved in statin-mediated cardioprotection; indeed, NO has been shown to activate mitochondrial KATP channels and inhibit mPTP (Jones et al. 2003). In addition to this anti-apoptotic mechanism, statinmediated inhibition of Rho kinase leading to activation of PI3K/Akt pathway also promotes survival of the myocardial tissue (Wolfrum et al. 2004, Hamid et al. 2007). On the other hand, statin-mediated cardioprotection seen upon the onset of reperfusion phase has been suggested to be linked to the activation of RISK pathway involving Akt/PKB-Erk2-PKC (Vilahur et al. 2009). Here, we showed that lipophilic simvastatin upregulated the expression of anti-apoptotic Bcl-2 whose content was decreased due to IRI. In line, simvastatin decreased the up-regulation of pro-apoptotic Bax in the ischemic/reperfused hearts. In addition, this S-mediated reduction of the pro-apoptotic and up-regulation of the anti-apoptotic mediators co-existed with heart function restoration (Fig. 3), indicating that abolishment of cardiac stunning may be associated with the reduced loss of cells due to apoptosis. To investigate which transcription factor may govern regulation of expression of genes of apoptosis, we analyzed expression of STAT3 known to inhibit caspase 3 activity and promote the expression of Bcl-2. Cheng et al. (2010) showed, that inhibition of RhoA GTPase in hepatocytes enhanced STAT3 activation, which resulted in reduction of apoptosis as evidenced by down-regulation of Bax expression, cyt $\mathrm{C}$ release and caspase- 3 acitivity and up-regulation of antiapoptic proteins $\mathrm{Bcl}-2$ and $\mathrm{Bcl}-\mathrm{X}_{\mathrm{L}}$. Recently, STAT proteins have emerged as crucial modulators of the outcomes of myocardial IRI. In fact, phosphorylation and thus activation of STAT3 has been shown to transmit a survival signal to the preconditioned myocardium (Hattori et al. 2001) and to attenuate adverse cardiac remodelling induced by myocardial infarction (Obana et al. 2010). In line, Negoro et al. (2000) have reported that inhibition of Janus kinase (JAK), an upstream activator of STAT3, resulted in deterioration of myocardial viability in acutely infarcted hearts. Furthermore, Thuc et al. (2010) have shown that hydrophilic pravastatin administered into perfusion solution both prior to global ischemia or at the beginning reperfusion suppressed apoptotic cell death, preserved mitochondrial membrane potential via up-regulation of the phosphorylation of Erk1/2, another kinase activating STAT-3. Likewise, rosuvastatin, another hydrophilic statin, increased the content of pSTAT3 after myocardial infarction due to activation of JAK-STAT pathway (Xu et al. 2010). In our study, we found out that the levels of total nonphosphorylated STAT3 upon simvastatin treatment were altered neither in the non-ischemic nor 
ischemic/reperfused hearts. On the other hand, it was capable of increasing the levels of pSTAT3 under baseline conditions. Since there was no difference in the expression of pSTAT3 between the simvastatin-treated and non-treated hearts subjected to IRI, it seems that activation of STAT3 is not the exclusive pathway leading to attenuation of apoptosis mediated by statins. It is plausible that statins as effective pharmacological agents intercept more than one signal leading to cell death. It should be also pointed out that statins have also been shown to exert pro-apoptotic action; they were found to stimulate apoptosis in cancer cell lines, primary cultured vascular muscle, and fibroblasts (Guijarro et al. 1998, Yokota et al. 2008). Consistent with these findings, replacement therapy with isoprenoids, whose synthesis is blocked by HMG-CoA reductase, was capable to overcome pro-apoptotic effects of statins, indicating that isoprenoid-mediated prenylation of the small GTPbinding proteins mediates this response (Guijarro et al. 1998). Although there are unresolved issues surrounding the regulation of apoptosis by the inhibition of HMG$\mathrm{CoA}$ reductase, our results have suggested that statins may limit this type of IRI-induced cardiomyocyte cell death. In addition, many issues related to statin administration (a choice of lipophilic/hydrophilic statin for certain pathological states; time of administration; dosage, etc.) are also needed to be further clarified.

\section{Conclusion}

5-day simvastatin treatment is likely to salvage viability of IR-injured heart by favouring the expression of the anti-apoptotic protein and down-regulating the proapoptotic markers. Simvastatin increased Bcl-2/Bax ratio which co-existed with the improved post-ischemic recovery of cardiac contractile function. Simvastatin did not influence the baseline non-ischemic levels of caspase3, Bax, Bcl-2, and up-regulated the content of cytochrome C. Furthermore, simvastatin-mediated inhibition of HMG-CoA reductase did not change the expression of the total non-fosforylated transcription factor STAT3. Nevertheless, the increased expression of pSTAT3-Thr ${ }^{705}$ in conditions of IRI, both in the treated and non-treated group but without significant distinction suggests that simvastatin-mediated attenuation of apoptosis involving HMG-CoA reductase inhibition is not dominantly linked with the up-regulation of pSTAT3. However, the significantly increased basaline levels of pSTAT3 after simvastatin treatment in contrast to control group implies that pleiotropic effects of statins influence STAT3 signalling in myocardium. Further experiments are needed to explore transcriptional events and target genes which regulate apoptotic cell death in statin-treated hearts subjected to ischemia/reperfusion injury. Irrespective of that, our findings strongly support the idea that statins could be used as cell viability increasing agents and thus they could be adopted in conditions of IRI, e.g. for treatment of subjects undergoing angioplasty or coronary artery bypass irrespective of the presence/absence of disturbances in lipid metabolism.

\section{Conflict of Interest}

There is no conflict of interest.

\section{Acknowledgements}

The authors are thankful to Mrs. Veronika Haššová, Iveta Blažíčková and Iveta Formánková for their technical assistance. This study was supported by grants VEGA SR 1/0620/10, 2/0054/11, 1/0638/12 and APVV-0523-10, APVV-0102-11.

\section{References}

ADAMEOVA A, HARCAROVA A, MATEJIKOVA J, PANCZA D, KUZELOVA M, CARNICKA S, SVEC P, BARTEKOVA M, STYK J, RAVINGEROVÁ T: Simvastatin alleviates myocardial contractile dysfunction and lethal ischemic injury in rat heart independent of cholesterol-lowering effects. Physiol Res 58: 449-454, 2009.

BELL RM, YELLON DM: Atorvastatin, administered at the onset of reperfusion, and independent of lipid lowering, protects the myocardium by up-regulating a pro-survival pathway. J Am Coll Cardiol. 41: 508-515, 2003.

BOENGLER K, BUECHERT A, HEINEN Y, ROESKES C, HILFIKER-KLEINER D, HEUSCH G, SCHULZ R: Cardioprotection by ischemic postconditioning is lost in aged and STAT3-deficient mice. Circ Res 102: 131$135,2008$.

BRAUNWALD E, KLONER RA: Myocardial reperfusion: a double-edged sword? J Clin Invest 76: 1713-1719, 1985. 
CHENG HL, SU SJ, HUANG LW, HSIEH BS, HU YC, HUNG TC, CHANG KL: Arecoline induces HA22T/VGH hepatoma cells to undergo anoikis - involvement of STAT3 and RhoA activation. Mol Cancer 9: 126, 2010.

DANIAL NN, KORSMEYER SJ: Cell death: critical control points. Cell 116: 205-219, 2004.

FARQUI TR, GOMEZ D, BUSTELO XR, BAR-SAGI D, REICH NC: Rac1 mediates STAT3 activation by autocrine IL-6. Proc Natl Acad Sci USA 98: 9014-9019, 2001.

FIERS W, BEYAERT R, DECLERCQ W, VANDENABEELE P: More than one way to die: apoptosis, necrosis and reactive oxygen damage. Oncogene 18: 7719-7730, 1999.

FLISS H, GATTINGER D: Apoptosis in ischemic and reperfused rat myocardium. Circ Res 79: 949-956, 1996.

FREEMAN DJ, NORRIE J, SATTAR N, NEELY RD, COBBE SM, FORD I, ISLES C, LORIMER AR, MACFARLANE PW, MCKILLOP JH, PACKARD CJ, SHEPHERD J, GAW A: Pravastatin and the development of diabetes mellitus: evidence for a protective treatment effect in the West of Scotland Coronary Prevention Study. Circulation 103: 357-362, 2001.

FREUDE B, MASTERS TN, ROBICSEK F, FOKIN A, KOSTIN S, ZIMMERMANN R, ULLMANN C, LORENZMEYER S, SCHAPER J: Apoptosis is initiated by myocardial ischemia and executed during reperfusion. J Mol Cell Cardiol 32: 197-208, 2000.

GUIJARRO C, BLANCO-COLIO LM, ORTEGO M, ALONSO C, ORTIZ A, PLAZA JJ, DÍAZ C, HERNÁNDEZ G, EGIDO J: 3-hydroxy-3-methylglutaryl coenzyme A reductase and isoprenylation inhibitors induce apoptosis of vascular smooth muscle cells in culture. Circ Res 83: 490-500, 1998.

HAMID SA, BOWER HS, BAXTER GF: Rho kinase activation plays a major role as a mediator of irreversible injury in reperfused myocardium. Am J Physiol 292: H2598-H2606, 2007.

HATTORI R, MAULIK N, OTANI H, ZHU L, CORDIS G, ENGLEMAN RM, SIDDIQUI MA, DAS DK: Role of STAT3 in ischemic preconditioning. J Mol Cell Cardiol 33: 1929-1936, 2001.

HERNÁNDEZ-PRESA MA, ORTEGO M, TUNÓN J, MARTÍN-VENTURA JL, MAS S, BLANCO-COLIO LM, APARICIO C, ORTEGA L, GÓMEZ-GERIQUE J, VIVANCO F, EGIDO J: Simvastatin reduces NF-kappaB activity in peripheral mononuclear and in plaque cells of rabbit atheroma more markedly than lipid lowering diet. Cardiovasc Res 57: 168-177, 2003.

IKEDA Y, YOUNG LH, LEFER AM: Rosuvastatin, a new HMG-CoA reductase inhibitor, protects ischemic reperfused myocardium in normocholesterolemic rats. J Cardiovasc Pharmacol 41: 649-656, 2003.

JONES SP, TESHIMA Y, AKAO M, MARBAN E: Simvastatin attenuates oxidant-induced mitochondrial dysfunction in cardiac myocytes. Circ Res 93: 697-699, 2003.

KAJSTURA J, CHENG W, REISS K, CLARK WA, SONNENBLICK EH, KRAJEWSKI S, REED JC, OLIVETTI G, ANVERSA P: Apoptotic and necrotic myocyte cell deaths are independent contributing variables of infarct size in rats. Lab Invest 74: 86-107, 1996.

LIAKOPOULOS OJ, CHOI YH, HALDENWANG PL, STRAUCH J, WITTWER T, DORGE H, STAMM C, WASSMER G, WAHLERS T: Impact of preoperative statin therapy on adverse postoperative outcomes in patients undergoing cardiac surgery: a meta-analysis of over 30,000 patients. Eur Heart J 29: 1548-1559, 2008.

MEIER CR, SCHLIENGER RG, KRAENZLIN ME, SCHLEGEL B, JICK H: HMG-CoA reductase inhibitors and the risk of fractures. JAMA 283: 3205-3210, 2000.

NEGORO S, KUNISADA K, TONE E, FUNAMOTO M, OH H, KISHIMOTO T, YAMAUCHI-TAKIHARA K: Activation of JAK/STAT pathway transduces cytoprotective signal in rat acute myocardial infarction. Cardiovasc Res 47: 797-805, 2000.

OBANA M, MAEDA M, TAKEDA K, HAYAMA A, MOHRI T, YAMASHITA T, NAKAOKA Y, KOMURO I, TAKEDA K, MATSUMIYA G, AZUMA J, FUJIO Y: Therapeutic activation of signal transducer and activator of transcription 3 by interleukin-11 ameliorates cardiac fibrosis after myocardial infarction. Circulation 121: 684-691, 2010.

PAN W, PINTAR T, ANTON J, LEE VV, VAUGHN WK, COLLARD CD: Statins are associated with a reduced incidence of perioperative mortality after coronary artery bypass graft surgery. Circulation 110: II45-II49, 2004. 
RAVINGEROVÁ T, ADAMEOVÁ A, KELLY T, ANTONOPOULOU E, PANCZA D, ONDREJČÁKOVÁ M, KHANDELWAL VK, ČARNICKÁ S, LAZOU A: Changes in PPAR gene expression and myocardial tolerance to ischaemia: relevance to pleiotropic effects of statins. Can J Physiol Pharmacol 87: 1028-1036, 2009.

SIMON AR, VIKIS HG, STEWART S, FANBURG BL, COCHRAN BH, GUAN KL: Regulation of STAT3 by direct binding to the Rac1 GTPase. Science 290: 144-147, 2000.

THUC LC, TESHIMA Y, TAKAHASHI N, NAGANO-TORIGOE Y, EZAKI K, YUFU K, NAKAGAWA M, HARA M, SAIKAWA T: Mitochondrial K(ATP) channels-derived reactive oxygen species activate prosurvival pathway in pravastatin-induced cardioprotection. Apoptosis 15: 669-678, 2010.

TONOLO G, MELIS MG, FORMATO M, ANGIUS MF, CARBONI A, BRIZZI P, CICCARESE M, CHERCHI GM, MAIOLO M: Additive effects of Simvastatin beyond its effects on LDL cholesterol in hypertensive type 2 diabetic patients. Eur J Clin Invest 30: 980-987, 2000.

VILAHUR G, CASANÍ L, PENA E, DURAN X, JUAN-BABOT O, BADIMON L: Induction of RISK by HMG-CoA reductase inhibition affords cardioprotection after myocardial infarction. Atherosclerosis 206: 95-101, 2009.

WEBSTER KA: Programmed death as a therapeutic target to reduce myocardial infarction. Trends Pharmacol Sci 28: 492-499, 2007.

WOLFRUM S, DENDORFER A, SCHUTT M, WEIDTMANN B, HEEP A, TEMPEL K, KLEIN HH, DOMINIAK P, RICHARDT G: Simvastatin acutely reduces myocardial reperfusion injury in vivo by activating the phosphatidylinositide 3-kinase/Akt pathway. J Cardiovasc Pharmacol 44: 348-355, 2004.

WRIGHT RA, FLAPAN AD, MCMURRAY J, SLATTERY J, WHITE HD ET AL.: Scandinavian simvastatin study (4S). Lancet 344: 1765-1768, 1994.

XU H, YANG YJ, QIAN HY, TANG YD, WANG H, ZHANG Q: Rosuvastatin treatment activates JAK-STAT pathway and increases efficacy of allogenic mesenchymal stem cell transplantation in infarcted hearts. Circ $J$ 75: 1476-1485, 2011.

YOKOTA K, MIYOSHI F, MIYAZAKI T, SATO K, YOSHIDA Y, ASANUMA Y, AKIYAMA Y, MIMURA T: High concentration simvastatin induces apoptosis in fibroblast-like synoviocytes from patients with rheumatoid arthritis. J Rheumatol 35: 193-200, 2008.

ZHAO ZQ, NAKAMURA M, WANG NP, WILCOX JN, SHEARER S, RONSON RS, GUYTON RA, VINTENJOHANSEN J: Reperfusion induces myocardial apoptotic cell death. Cardiovasc Res 45: 651-660, 2000. 